\title{
Understanding the Organizational Impact of Radio Frequency Identification Technology: A Holistic View
}

\author{
Xihui "Paul" Zhang \\ Assistant Professor of Computer Information Systems \\ College of Business \\ University of North Alabama \\ Florence, AL 35632 \\ Xzhang6@una.edu \\ David W. Nickels \\ Associate Professor of Computer Information Systems \\ College of Business \\ University of North Alabama \\ Florence, AL 35632 \\ dwnickels@una.edu \\ Thomas F. Stafford \\ Associate Professor of MIS \\ Fogelman College of Business and Economics \\ University of Memphis \\ Memphis, TN 38152 \\ tstaffor@memphis.edu
}

\begin{abstract}
The adoption and deployment of radio frequency identification technology (RFID) in retail supply chains results in an influx of data, supporting the development of better information and increased knowledge. This impacts not only an organization's information technology infrastructure, but also the quality and timeliness of its business intelligence and decisionmaking. This paper provides an introduction to RFID technology and surveys a variety of its applications, then examines and discusses the impact of RFID technology on organizational IT infrastructure, business intelligence, and decision-making. Propositions are advanced to provide the basis for the development of specific hypotheses to be empirically tested in future studies, and a conceptual research framework for understanding the organizational impact of RFID technology is proposed.
\end{abstract}

Keywords: Radio frequency identification, RFID, IT infrastructure, Business intelligence, Decision making, Retail supply chain, Supply chain management. 


\section{Introduction}

Radio frequency identification (RFID) is a technology that uses radio frequency transmissions to uniquely identify objects (Xiao et al., 2007). The concept of radio identification is not new, having originated during World War II as a method for armed forces to quickly identify friendly ships and airplanes in battle (Levinson, 2003). In more recent years, RFID applications have enjoyed enormous attention in industry and research (Loebbecke, 2007), with prominent retailers such as Wal-Mart, Target, Best Buy and Home Depot, in addition to governmental agencies such as the U.S. Department of Defense, adopting RFID to manage supply chain operations. Decreased cost of deployment and increased scope of applications, arising from the evolving maturity of the technology, contributes to RFID's rising popularity (Want, 2004).

Barcodes have been the primary form of identification in retail supply chains since the mid-1970s (Delen et al., 2007), but this technology is limited by its line-of-sight data acquisition (Angeles, 2005). However, RFID technology is poised to replace barcodes in product identification applications. As shown in Table 1, RFID technology offers numerous advantages over barcodes for product identification.

\begin{tabular}{|l|l|l|}
\hline Table 1 - RFID vs. Barcode (adapted from Delen et al., 2007 and Loebbecke, 2007) \\
\hline & \multicolumn{1}{|c|}{ RFID } & \multicolumn{1}{c|}{ Barcode } \\
\hline Line of sight & Not required & Required \\
\hline Reading range & Long & Short \\
\hline Simultaneous multiple reads & Yes & No \\
\hline Durability & High & Low \\
\hline Price & High & Low \\
\hline Item differentiation & Possible & Not possible \\
\hline Information state & Updatable & Static \\
\hline Has power source & Yes (active tags) & No \\
\hline
\end{tabular}

RFID technology can provide multiple benefits to firms. For instance, it facilitates absolute inventory control both in-store and at various supply chain stocking points, resulting in operational efficiency improvements, cost reductions, and margin increases (Levinson, 2003; Sengupta and Sethi, 2007). RFID also reduces counterfeiting and theft loses (Dos Santos and Smith, 2008; Lewis, 2004). Eventually, RFID has the potential to reduce the reliance upon human cash register operators in checkout operations in stores (CILT World, 2004).

Many discussions of forthcoming implementations revolve around the transparency that RFID will provide in retail supply chains, achieved through the provision of detailed information regarding the real-time physical location of goods as they move from the manufacturer to the point of sale (Angeles,
2005). Curtin et al. (2007) suggest that using RFID-enabled supply chain management systems may be an important means of optimizing agility, adaptability, and alignment. In this context, agility refers to the capability of a firm to react promptly to changes in demand or supply, adaptability concerns the ability to react effectively to changing market structures and strategies, and alignment is the capability to reconcile the interests of all each firm in a given supply chain such that companies optimize the chain's performance through maximizing their own interests (Lee, 2004). RFID-enabled agile, adaptable and aligned supply chains provide partnered companies with a sustainable competitive advantage" (Lee, 2004, p. 104).

Another potential benefit for organizations adopting RFID technology in supply chain operations is cycle time reduction in decision 
making (Asif and Mandviwalla, 2005). This is because resulting real-time information provided by RFID enables improvement in timeliness and quality of organizational decisions (Sellitto et al., 2007; Watson et al., 2006), which allows organizations to refine operational performance and ultimately to improve their profitability (Curtin et al., 2007; Lewis, 2004). In today's markets, faster decisions are automatically better because of the advantages of "scope" (e.g., Porter, 1990), in which faster, more agile competitors gain advantages related to speedier engagement with dynamic retail market conditions (Sellitto et al., 2007).

Even so, the adoption of RFID technology is not without potential difficulties. Barriers to widespread adoption of RFID include issues related to standardization, interoperability, cost, forward compatibility, lack of familiarity, business process reengineering, and integration (Asif and Mandviwalla, 2005; Viehland and Wong, 2007). Despite these potential barriers, the adoption and deployment of RFID seems an inevitable supply chain phenomenon, especially in retail supply chains.

RFID applications are increasingly prevalent, and the technology has improved in a variety of aspects as it diffuses to users. Meanwhile, deployment costs are also decreasing. These factors, taken together, have the potential to increase RFID adoption and deployment rates in organizations. To date, a few studies have tried to investigate the impact of RFID adoption and deployment on retail supply chains. For instance, Soon and Gutiérrez (2008) explored the effects of RFID implementations on supply chain management, while Hardgrave et al. (2009) studied the impact of RFID on inventory accuracy, and Bottani et al. (2009b) investigated the impact of RFID on logistics processes. Unfortunately, none of this prior work has achieved a holistic view of RFID's impact on organizations, especially along the lines of IT infrastructure, business intelligence, and decision making. As such, it is imperative that more research be conducted, and this study provides a framework to support future attempts to fill this gap.

We believe that use of RFID technology enables a chain of information-based improvements in managerial decisions about supply chain deployment. We refer to this concept as "the IT Decision Chain" to convey the notion of a chain reaction of improved operational decisions supported by RFID use and the resulting geo-temporal data flows and marketplace intelligence provided to decision makers by RFID systems. Robust data flows from RFID-enabled retail supply chain systems lead to better business intelligence and decision making fueled by superior market information (Sellitto et al., 2007). Niederman et al. (2007) suggest that we integrate RFID data into business processes and develop feedback-loops that generate more efficient and effective business processes and decision making.

As an advanced information technology, RFID technology clearly holds the potential to influence organizational design and decision making. Huber's (1990) conceptual theory of the effects of advanced information technologies on organizational design, intelligence, and decision making focuses on the influence of devices that transmit, manipulate, analyze, or exploit information. Huber (1990) advances fourteen propositions regarding the influence of such technologies on organizational design, intelligence, and decision making, and, as demonstrated in Figure 1, the broad logic of Huber's propositions is that availability of advanced information technology results in its use, which in turn leads to increased information accessibility. Information accessibility subsequently impacts organizational design, and the convergence of these two key factors leads to improvement in intelligence and subsequent decision making (Fulk and Boyd, 1991).

Building upon Huber's conceptualization, this paper proposes "the IT Decision Chain" initiated by RFID use, including its effects on an organization's IT infrastructure, business intelligence, and ultimately, decision making 
processes. By itself, RFID technology is not sophisticated. Its widespread adoption and use, however, will significantly alter both individual organizations and society as a whole. This is because successful RFID deployment involves changes in firm organization, business processes, and technological applications (Niederman et al., 2007).

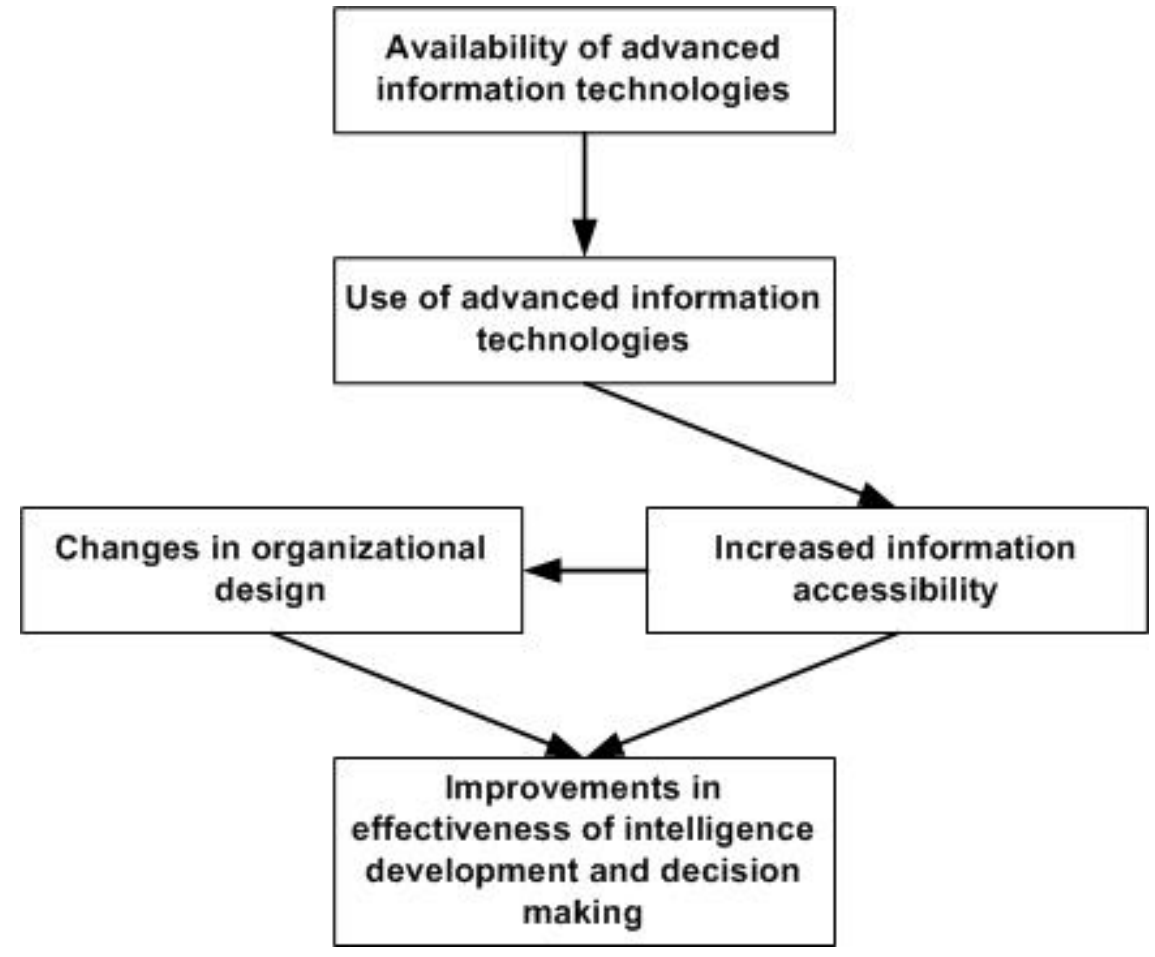

Figure 1 - Conceptual Theory of the Effects of Advanced Information Technologies on Organizational Design, Intelligence, and Decision Making (adapted from Huber, 1990)

The following exploration and discussion of the potential organizational impacts of RFID adoption and use includes an introduction to RFID technology and a survey of its applications. This is followed by a detailed description of RFID's potential impact on organizational IT infrastructure, business intelligence, and decision making. As part of this examination, research propositions which can serve as a basis for the development of specific hypotheses to be empirically tested in future studies are advanced. Lastly, a conceptual research framework is provided to support a continued exploration of the organizational impact of RFID technology.

\section{RFID Technologies} Applications

\section{RFID Technologies}

RFID systems function as a kind of sensor network that uniquely identifies objects using radio frequency transmissions (Xiao et al., 2007). The basic components of an RFID system are tags, readers, and an application system. These components and their interactions are illustrated graphically in Figure 2. 


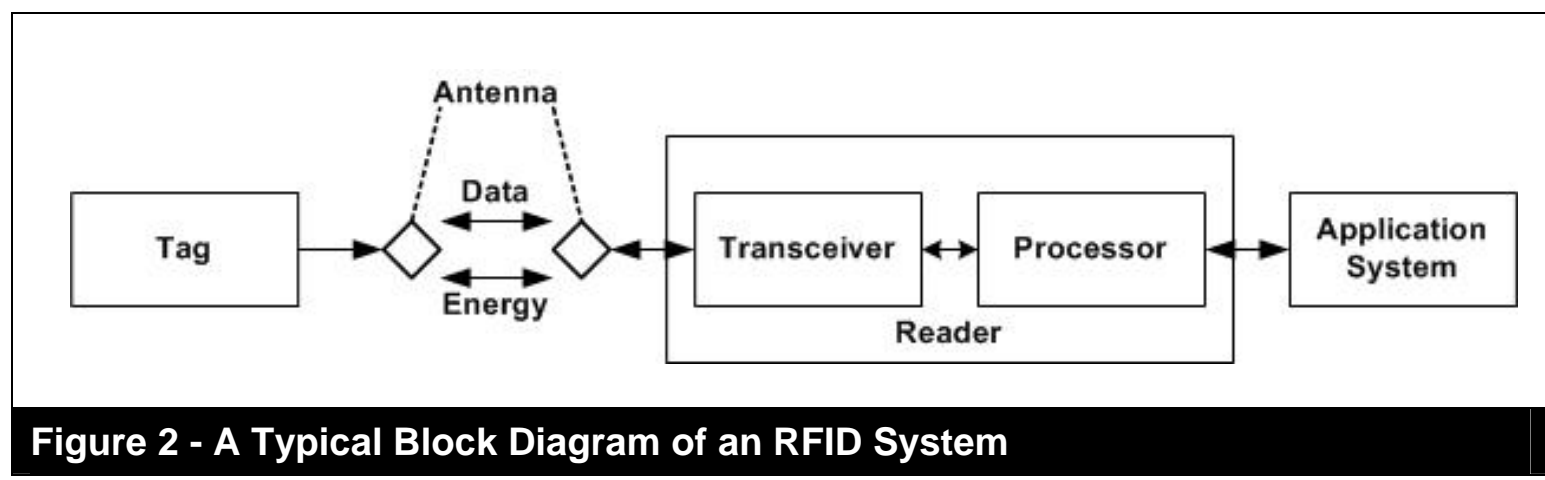

A tag is a chip that is attached to or embedded in an object and contains unique object identification information. A reader, which interrogates tags for their unique identification information, consists of antennas, transceivers, and processors. Antennas allow data and energy exchange between a reader and its corresponding tags, while transceivers and processors encode and decode data. Application systems catalog tag information obtained from the readers and supplement more information obtained from other servers, e.g., an object name service (ONS) server (Asif and Mandviwalla, 2005; Xiao et al., 2007).

Tags vary in size. They typically range from the size of a grain of rice to two-inch squares (Ayre, 2005). Recently, tags at the minute particle level have been reported (Hornyak, 2008). RFID tags can take a variety of forms, similar in shape to a watch battery, a flat disk, a thin cylinder, a cracker, a credit card, or even a cigarette pack (Keshiwani, 2005). In addition to an antenna and optional power source, a typical tag contains a chip which store data (up to 1,024 bits) using one of a variety of naming schemes (Chawathe et al., 2004). One of the most widely adopted, EPC96, is based on a 96-bit code.

As shown in Table 2, the EPC-96 scheme divides 96 bits into four parts including a header, an EPC manager number, an object class, and a serial number. The electronic product code (EPC) is the minimum information that enables a tag to identify an associated product (Smith and Konsynski, 2003; Want, 2004). The permutations permitted with this data structure can serve the needs of over 260 million potential RFID users; each potential RFID user can have naming access to over 16 million different product classes; and each product class can contain over 680 billion individual items. Compact in storage and operation, EPC-96 can nonetheless support identification of 1.5 quintillion (http://www.eforceglobal.com).

objects

Tags can be active, passive, or semi-passive (Angeles, 2005). Active tags are powered, using on-board batteries to support microchip operations and signal broadcasts. Passive tags, with no on-board power sources, are powered by reader-broadcast radio wave queries that induce a current in the tag's antenna, which then powers the chip for processing. Lastly, semi-passive tags use both on-board batteries and electromagnetic waves from readers for processing (Angeles, 2005).

Tags differ in weight, cost, range, and useful life. With fewer dedicated components, passive tags are lighter and less expensive than active tags, and they provide nearly unlimited operational lifetime. Their reading range, however, is very limited ( $\mathrm{Ni}$ et al., 2004). Limits on read range depend on tag type, reader power, and the radio frequency used for reader-tag communications (Angeles, 2005). Passive tags typically have smaller ranges since they rely on outside power, while active tags, usually having their own power sources, have larger ranges. Read range can be increased by choosing higher operating frequencies that can be read over longer distances, but this requires more reader energy output (Angeles, 2005). 


\begin{tabular}{|l|l|l|l|l|}
\hline \multicolumn{1}{|c|}{ Table 2 - Basic Format of EPC-96 Scheme } \\
\hline \multicolumn{1}{|c|}{ Partition } & \multicolumn{1}{|c|}{ Header } & \multicolumn{1}{c|}{$\begin{array}{l}\text { EPC Manager } \\
\text { Number }\end{array}$} & Object Class & Serial Number \\
\hline Function & $\begin{array}{l}\text { Identifies the length, type, } \\
\text { structure, version, and } \\
\text { generation of the EPC }\end{array}$ & $\begin{array}{l}\text { Entity responsible for } \\
\text { maintaining subsequent } \\
\text { partitions }\end{array}$ & $\begin{array}{l}\text { Identifies a } \\
\text { class of objects }\end{array}$ & $\begin{array}{l}\text { Identifies } \\
\text { instance }\end{array}$ \\
\hline Assigned by & EPCglobal & EPCglobal & $\begin{array}{l}\text { EPC Manager } \\
\text { Owner }\end{array}$ & $\begin{array}{l}\text { EPC } \\
\text { Manager } \\
\text { Owner }\end{array}$ \\
\hline Format & 01 & $0203 \mathrm{D} 2 \mathrm{~A}$ & $916 \mathrm{EBB}$ & $0719 \mathrm{BAE} 03 \mathrm{C}$ \\
\hline Length & 8 bits & 28 bits & 24 bits & 36 bits \\
\hline Total number & 256 & $268,435,456$ & $16,777,216$ & $687,194,767,361$ \\
\hline
\end{tabular}

\section{RFID Applications}

RFID readers communicate directly with tags. Upon receiving a tag's radio transmission, the reader performs error checking, and then communicates with an application system for further guidance. Early RFID adopters such as Wal-Mart and U.S. Department of Defense demonstrate the magnitude of potential benefits and enable informed speculation grounded in current and planned future use in supply chains.

Since RFID technology is still under development, there are numerous emerging applications (Weinstein, 2005). Until adoption levels reach market saturation, it will be difficult to define RFID's potential scope (Smith and Konsynski, 2003). Indeed, the implications for retail supply chain applications, alone, are only recently being investigated (Sellitto et al., 2007). This section surveys a range of such uses, including supply chain management, electronic payment systems, transportation baggage handling, and human, animal or equipment identification tagging.

Current RFID implementation permits product tracking throughout the supply chain (Weinstein, 2005). Products are identified and located temporally and geographically from upstream suppliers to downstream partners to retail points of sale, including the warehouse stocking points in between. This real-time or near real-time informational transparency is unmatched by any competing supply chain management technology (Sellitto et al., 2007). Such RFID implementations enable reduced order cycle time, increased forecast accuracy, and more flexible response to demand fluctuations (Hannula and Pirttimaki, 2003; Smith and Konsynski, 2003; Van der Vorst et al., 1998). The net result is timely, high quality decision making.

Speculation regarding future consumer sector applications includes the possibility of attendant-free automated supermarket cash register checkouts (CILT World, 2004). The feasibility of this potential application is supported by existing RFID-based payment systems such as those used for toll roads. A prominent provider, SunPass (www.sunpass.com), equips cars with RFID transponders and tags with unique serial numbers, allowing accurate usage-based billing. In like manner, fuel key payment systems such as those used by Exxon and Phillips 66 utilize RFID technology. Tags that are typically attached to customer key rings enable fuel pump transactions and convenience store purchases without the use of cash or credit cards, subsequently avoiding delays at cashier workstations (Smith and Konsynski, 2003).

RFID options for the identification of people or animals include attaching a tag to the body or implanting it under the skin. Tagging animals or people is more challenging than tagging inanimate objects, since animals and people can move independently. There are also ethical issues related to the tagging of living organisms, arising from the capability of tracking their independent movements, which raises privacy concerns. Peoples' perceptions 
of privacy risks (perceptions of the probability that a privacy breach will occur) and privacy risk harms posed by RFID technology (perceptions of the level of damage that would occur in the event of a privacy breach) can have a significant negative impact on their willingness to adopt and use the technology (Cazier et al., 2008). Sengupta and Sethi (2007) observed that even IS researchers cannot fully resolve privacy concerns related to RFID technology. Privacy notwithstanding, ethical reasons for human tagging do exist, such as safety and welfare assurance for patients who need close monitoring, or for the public in the case of convicted criminals on parole. For example, Janz, Pitts, and Otondo (2005) documented improved patient handling flows with the implementation of a trauma unit patient tracking system using ankle bracelet RFID tags.

Equipment, document, and baggage tracking applications that could benefit from RFID implementations are also widely used in hospitals, libraries, and airports, respectively. Hospitals can use RFID technology to track crucial pieces of equipment, making them easy to locate in case of an emergency. Libraries can tag books to assist in locating them, automating the check-out and check-in processes, and preventing theft (Weinstein, 2005). Airports in San Francisco, Seattle, Las Vegas, and Houston have already begun experimenting with RFID-enabled baggage tracking to enhance curbside check-in and reduce or eliminate manual sorting (Smith and Konsynski, 2003).

One of the latest and most interesting RFID applications is the Coca Cola Company's Freestyle drink dispenser, which has been deployed at fast-food outlets in California, Georgia, and Utah (Weier, 2009). The unique dispensers each contain 30 cartridges of flavorings that can be mixed in up to 100 different drink combinations. The cartridges are tagged with radio frequency ID chips, and each dispenser contains an RFID reader. The dispenser collects data on what customers are drinking and transmits that information each night over a private wireless network to
Coca Cola's SAP data warehouse system in Atlanta. The company uses this data to develop reports that assess how new drinks are performing in the market, to identify differences in regional tastes, and to help fast-food outlets decide which drinks to serve" (Weier, 2009, p. 30).

\section{RFID as IT Decision Chain Initiator}

RFID technologies and the resulting data flows set off a chain reaction of enhanced information, business intelligence, and knowledge for organizational decision makers, simultaneously impacting IT infrastructure as well as the quality and timeliness of its business intelligence and decision making. In a panel on the topic of exploring the future of RFID technologies at the 2007 Americas Conference on Information Systems (AMCIS), panel members observed that potential for vastly increased data flows arising from RFID-enabled applications will lead to research on new methods of data storage, mining and warehousing, as well as new methods for optimizing business process such as supply chains and inventory control (Sengupta and Sethi, 2007).

The effects of RFID can be divided into three major categories: automation, transformation, and information (Melville et al., 2004). Automation effects lead to process efficiency, transformation effects lead to process redesign, and information effects lead to better and quicker information (Melski et al., 2008). Curtin et al. (2007) also proposed a research agenda for the study of RFID adoption (development, adoption and implementation by organizations), usage (use, support and evolution with organizations and alliances), and impact (how it influences individuals, business processes, organizations and markets). Asif and Mandviwalla (2005) have suggested that new IS research can arise from investigating new ways to manage, use and control RFIDgenerated data.

Our study focuses on the potential impact of RFID on organizational IT infrastructure, 
Understanding the Organizational Impact of Radio Frequency Identification Technology/ Zhang et al.

business intelligence, and decision making. Specifically, in the following section, we examine these effects and outline a series of propositions for future empirical testing. We also illustrate an "IT Decision Chain" effect, initiated by the adoption and deployment of RFID technology, along with an accompanying conceptual research framework.

\section{RFID Effect on IT Infrastructure}

RFID technology use poses a variety of challenges for organizational IT infrastructure. Depending on tag reader query rates for passive tags, or broadcasting rate for active tags, substantial increases in system data volumes can result from RFID-enabled device usage. In general, a supply chain's visibility is positively related to its data granularity (Melski et al., 2008), and higher supply chain visibility is considered to be better, but this visibility will require higher data granularity and the result will be the generation of more data. RFID tags can provide a source of streamed data with real-time, continuous, rapid, time-varying sequences of data elements. These elements will either be ordered (implicitly by arrival time or explicitly by timestamp) or unpredictable and unbounded (Golab and Ozsu, 2003). Continuous and extensive data streams can severely test an organization's IT infrastructure in terms of data capture, data management, and data analysis.

One streaming-related challenge is the multiplicity of devices typical of large-scale implementations. While tags and readers generate individual data streams, data streaming networks fed by multiple RFID devices have multiple data streams. Managers may not want all of the data that an extensive RFID implementation can produce. Sheer data volume could make usage impractical, or the data itself could include redundancies or have limited immediate utility. Real-time data flows can produce constant streamed updates on previously-identified objects at a level of detail not always required for business purposes. Hence, data filtering, aggregation, and abstraction functions that summarize tag reads prior to network transmission can be critical to successful RFID implementation. By implementing an RFID system and evaluating its performance, Zang et al. (2008) show that aggregated data processing instead of raw data processing improves operational efficiency. Dutta et al. (2007) suggest that Edgeware, a combination of hardware and software, can be used to supervise an RFID network, subsequently aggregating and filtering the raw data, and transmitting the relevant data to a central application systems for further processing. Thus, we propose:

Proposition 1: Use of RFID
technology will require IT
infrastructure capacity for data filtering,
data aggregation, and data
abstraction functions employed at the
data source.

As RFID technology is deployed, more data will be collected at the data sources and transported to corporate data centers for storage and processing. Even after filtration, aggregation, and abstraction, data volumes generated by large-scale RFID implementations will be considerable. Such volumes can tax an organization's network bandwidth and storage capacity, which may make it impractical for an organization to maintain an acceptable level of operational effectiveness and efficiency. Furthermore, the problems associated with large datasets are not restricted to the data flow, itself; they also impact to the storage, maintenance, and use of the data (Delen et al., 2007). As such, it might be wise to distribute the processing load for RFID data streams across a wider network instead of transmitting the entire data feed to central processing and storage. This will reduce bandwidth requirements and shorten processing times at corporate data centers. Additionally, the need of short response times to RFID data streams (e.g., real-time systems) requires portions of the application to run on edge servers, effectively shifting intelligence and decision responsibility from the center to the network edge (Clauberg, 2004). As a result, an organization's enterprise architecture is 
expected to become more distributed to effectively and efficiently respond to increased data flow levels (Levinson, 2003). Hence, we suggest:

Proposition 2: Use of RFID
technology will result in enterprise
architectures that are more distributed
in processing and in fulfilling
intelligence and decision responsibility.

Data transmission methods are impacted by the use of RFID technology as well. Firms often prefer batch mode data transmission for economic reasons, resulting in periodic uploads of information on an hourly, shiftwise, daily, or even weekly basis (Angeles, 2005). However, to realize the decisionmaking benefits of information-rich real-time data streams, real-time transmission becomes more desirable. This suggests that:

Proposition 3: Use of RFID technology will result in an increased preference for real-time data transmission in organizations.

Just as with data stream capture, transmission, and storage, data analysis is impacted in large-scale RFID implementations. Real-time decision making necessitates extensive RFID data streams; this, in turn, implies a need for enhanced analysis techniques with data mining tools to identify hidden trends and patterns (Dubey, 2005; Gonzalez et al., 2006). Therefore:

Proposition 4: Use of RFID technology will result in the increased use of data mining technologies in organizations.

\section{RFID Effect on Business Intelligence}

Business intelligence results from production of actionable information that spans both internal processes and external market characteristics. It is increasingly difficult to produce such intelligence because accurate capture of internal and external changes is threatened by the very dynamism that makes such monitoring essential (Brackett, 1999; Hannula and Pirttimaki, 2003; Vedder et al., 1999). Hence, there is a disconnect between the growing demand for intelligence and the increasing volatility of data to be captured in support of that goal. RFID systems can help close the gap, by improving quantity, quality, and timeliness in the capture of market and operational information.

Real-time tracking and visibility capabilities will be greatly improved when the use of RFID technology evolves from pallet tagging to individual case tagging, and finally to specific item tagging (Kamoun, 2008). Results from a simulation-based study (Bottani, 2008) as well as a field study (Bottani et al., 2009a) suggest that data captured in an RFID-enabled supply chain can offer value-added information for process optimization. RFID technology can also serve to synchronize information flows with product flows in a given supply chain, which will provide a better level of information integration between supply chain members (Wamba and Boeck, 2008). Provided that IT infrastructure is equal to the task of effectively and efficiently capturing, managing, and analyzing ever-increasing volumes of data, RFID technology can provide timely, accurate, and comprehensive business intelligence (Curtin et al., 2007; Delen et al., 2007; Sellitto et al., 2007). Hence:

Proposition 5: Use of RFID
technology will
accurate result in more
business intelligence in organizations.

Proposition 6: Use of RFID technology will result in more timely business intelligence in organizations.

\section{RFID Effect on Decision Making}

It is reasonable to believe that higher quality business intelligence leads to higher quality decisions, and that timely business intelligence also leads to timely decisions (Fulk and Boyd, 1991; Huber, 1990; Sellitto et al., 2007). The use of RFID technology should result in changes in the IT infrastructure, which will, in turn, enable improvements in business intelligence, ultimately supporting improvements in decision making. This is the rationale for the 
proposed RFID-enabled "IT Decision Chain" shown in Figure 3.

The power and ultimate promise of RFIDbased retail supply chains lies in the ability to base decision-making on accurate, high quality information arising from real-time monitoring of critical product and service flows (Angeles, 2005; Sellitto et al., 2007). Potentially, such use results in timely, accurate, comprehensive business intelligence, which enables higher quality, more timely decisions (Friedman and Strange, 2004; Watson et al., 2006). Thus, we propose:

Proposition 7: Use of RFID technology will result in higher quality managerial decisions.
Proposition 8: Use of RFID technology will reduce the amount of time required for decision making.

\section{A Conceptual Research Framework}

The proposed conceptual research framework describes the indirect effect of RFID technology usage on managerial decision making. As discussed above, Figure 3 illustrates a sequential chain of influences in which use of RFID technology results in IT infrastructure changes, which in turn lead to improvements in business intelligence, and ultimately enables improvements in decision making. Quality and timeliness are two major metrics for assessing improvements in business intelligence and decision making.

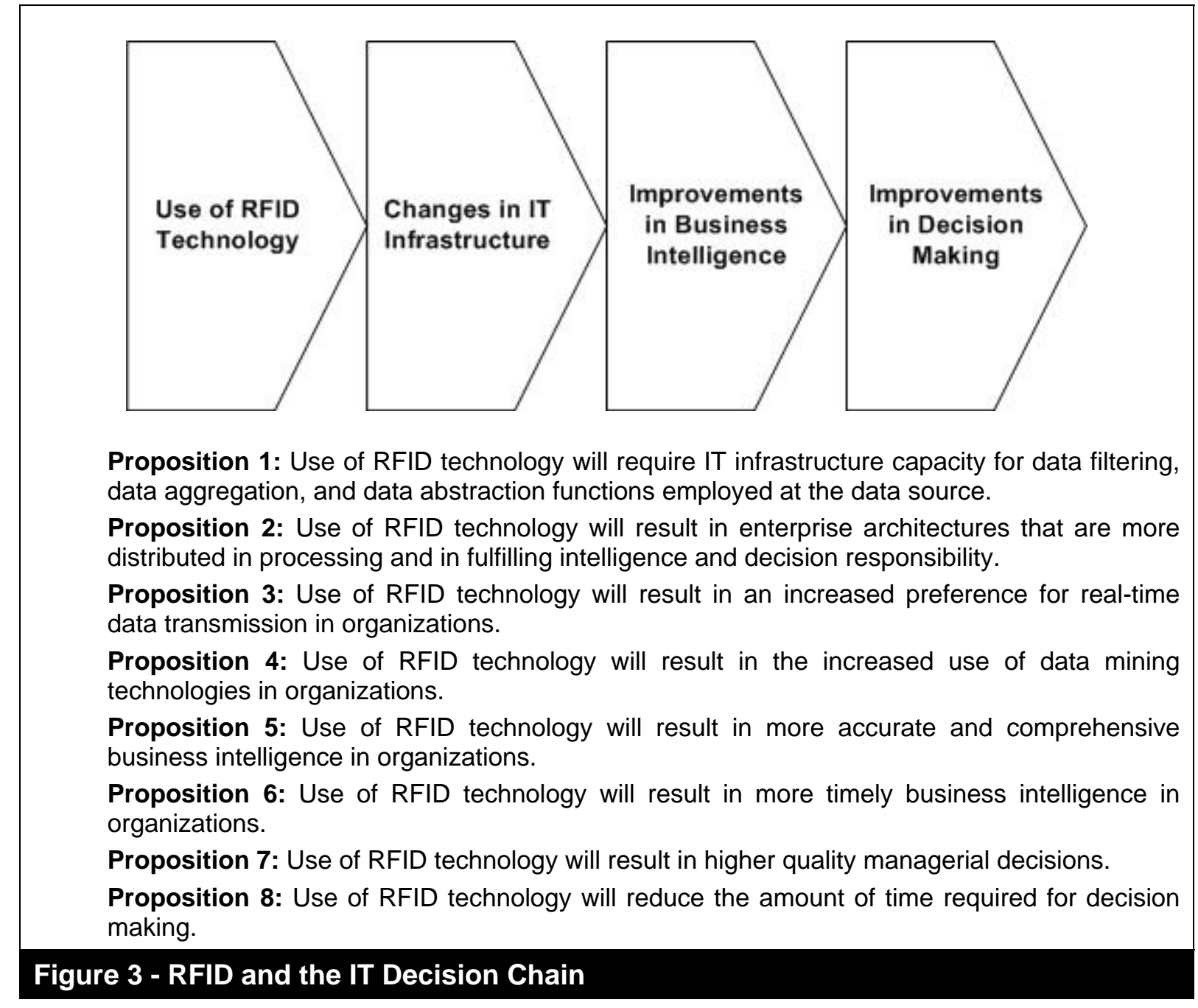




\section{Discussion}

Melski et al. (2008) argue that the future potential of RFID applications lies in the development of supply chain visibility. They propose a four-step approach to assess RFID visibility effects: Visibility (How RFID systems increase supply chain visibility), Awareness (How increased visibility leads to greater awareness of current operational sequences), Decision (How awareness of real-world processes improves decisions), and Results (How decisions affect business goals). Sharing of information among supply chain participants can provide real-time or nearreal-time inventory visibility. This can result in cost reductions that lead to improved competitiveness on the part of cooperating supply chain partners (Niederman et al., 2007). Hence, benefits of deploying RFID can be tangible or intangible (Kamoun, 2008), as shown in Table 3.

\begin{tabular}{|c|c|}
\hline Tangible & Intangible \\
\hline $\begin{array}{ll}\text { - } & \text { Improved operational efficiency \& } \\
& \text { effectiveness } \\
\text { - } & \text { Improved productivity } \\
\text { - } & \text { Reduced logistic \& labor costs } \\
\text { - } & \text { Reduced out-of-stocks } \\
\text { - } & \text { More accurate inventory \& shipping data } \\
\text { - } & \text { Enhanced forecasting \& replenishment } \\
\quad \text { diversion }\end{array}$ & $\begin{array}{l}\text { - } \quad \text { Better visibility throughout supply chain } \\
\text { - } \quad \text { Increased data accuracy } \\
\text { - } \quad \text { Better customer satisfaction } \\
\text { - } \quad \text { More accurate receiving time } \\
\text { - } \quad \text { Compliance with external mandates } \\
\quad \text { peamless collaboration with trading } \\
\text { - } \quad \text { Competitive advantage }\end{array}$ \\
\hline
\end{tabular}

The challenges of adoption and the subsequent effective use of RFID in supply chains are substantial for retail organizations. Critical factors that may affect the adoption of RFID technology include marketplace competition, the influence of transaction partners, the industry environment, costs, supply chain integration strategies, complexity of the RFID technology, itself, and mutual standards (Chang et al., 2008). Currently, costs are a major concern, as tagging even at the case level might incur negative economic results (Bottani and Rizzi, 2008). The main RFID cost components include those for software, hardware, and installation, operations, administration and maintenance (Kamoun, 2008).

As shown in Table 4, Asif and Mandviwalla (2005) have identified a list of key issues associated with RFID adoption, as shown in Table 4, which is based on an extensive detailed literature review, informal interviews with industry executives and vendors, the results of a panel discussion, the results of an industry forum involving key practitioners, and a laboratory experiment using current RFID technologies.

The theoretical advantages of real-time object location and identification are clear, but the support technologies required to handle these massive influxes of streamed data and subsequent information production are less obvious. It is one thing to learn that RFID in a supply chain will let us know exactly where everything is. It is another thing entirely, to grasp the magnitude and the deployment difficulty of the IT infrastructure upgrades needed to realize these benefits, and yet another to comprehend the full value of the investment in terms of decision process synergy and effectiveness.

Business value from RFID use lies not in the technology itself, but rather in the creative use of the data. The real value of these data is in leveraging this information to make better business decisions (Delen et al., 2007). The business value of RFID can be fully realized only when RFID technology is seamlessly integrated with not only business processes, but also with people, policies, and organizational structures (Dutta et al., 2007). 
Hardgrave et al. (2007) suggest that RFID technology helps create greater business values when adopting organizations more deeply assimilate it, especially when the RFID assimilation goes beyond technology deployment and data understanding. In the same vein, Faupel et al. (2008) assess the performance-enhancing impact of RFID with three effects: automation (automated acquisition of information), informatization (increased information quality), and transformation (re-engineered and new business processes). Their findings indicate that automation alone does not systematically contribute to performance enhancement assessed with variables such as lead time and production downtime.

\begin{tabular}{|l|l|}
\hline \multicolumn{1}{|c|}{ Table 4 - Key Issues of RFID Adoption (adapted from Asif and Mandviwalla, 2005) } \\
\hline \multicolumn{1}{|c|}{ Issue } & \multicolumn{1}{c|}{ Explanation } \\
\hline $\begin{array}{l}\text { Hardware and software are a significant } \\
\text { expenditure }\end{array}$ & Costs of hardware, software, and a special IT infrastructure \\
\hline Training and integration & Worker training and system integration \\
\hline Item vs. pallet tagging & $\begin{array}{l}\text { Item-level tagging requires more tags and also generates more } \\
\text { data, demanding more sophisticated data filters and pipelines as } \\
\text { well as more complex software layers and IT architecture }\end{array}$ \\
\hline Standards & $\begin{array}{l}\text { Standards, an essential condition for interoperability and a driver } \\
\text { for cost reductions, are not yet available }\end{array}$ \\
\hline Security & $\begin{array}{l}\text { Hard to design adequate cryptographic algorithms for data } \\
\text { security; hard to identify authentic readers }\end{array}$ \\
\hline Privacy and legislation & Privacy concerns and threat of legislative oversight \\
\hline Organizational readiness & $\begin{array}{l}\text { Organizational structure and culture could impede smooth } \\
\text { conversion to RFID }\end{array}$ \\
\hline Accuracy & Tag collision can result in misreads or no reads \\
\hline Implementation challenges & $\begin{array}{l}\text { Implementing RFID is not as straight forward as implementing an } \\
\text { off-the-shelf solution }\end{array}$ \\
\hline $\begin{array}{l}\text { Managing projects: Operations to } \\
\text { marketing to systems }\end{array}$ & $\begin{array}{l}\text { Aim to take complete advantage of an RFID-enabled supply } \\
\text { chain }\end{array}$ \\
\hline $\begin{array}{l}\text { Information sharing and channel } \\
\text { alignment }\end{array}$ & \begin{tabular}{l} 
Share timely information with various actors in a supply chain \\
\hline
\end{tabular} \\
\hline
\end{tabular}

RFID technology implemented in supply chains has positive performance impacts in terms of shortening the merchandise's movement time in the supply chain, decreasing labor requirements, and enhancing data quality and subsequent service offerings (Loebbecke, 2007). In line with Curtin et al. (2007), we recommend that future research address specific questions on how adoption and use of RFID technology can actually transform an organization's IT infrastructure capability, business intelligence efficiency, and decision making effectiveness.

There is a faddish quality to the current popularity of RFID that can obscure the pragmatic issues of deployment. In our judgment, the benefits of adoption are well worth the cost and effort, but careful planning is needed to ensure that necessary IT infrastructure upgrades and modifications are budgeted for and included in project schedules. To be successful, organizations can follow a four-stage model when they adopt and deploy RFID technology: research, experimentation, limited deployment, and general deployment (Fichman, 2001; Jeyaraj et al., 2008).

If implemented wisely, RFID data streams can greatly improve the quality and timeliness of business intelligence, enabling effective decision making in dynamic retail channels. But poorly considered deployment could result in cascading issues generated from organizational and infrastructural challenges that may tax IT capabilities. Focus on potential strategic benefits must be balanced 
by assessment of tactical networking and data center connectivity needs.

\section{Conclusion}

The contribution of this paper is twofold. First, it provides academic RFID researchers with a conceptual research framework and a series of propositions that can guide future studies. Secondly, it has a cautionary function, alerting business managers to the full depth and breadth of potential issues arising from RFID adoption. The value of RFID-enabled real-time response to a full range of operational and competitive factors is undeniable, but the way forward to achieving these ends becomes clear only with consideration of the implications of the full "IT Decision Chain," that begins with RFID chips in products and objects, extends to the requisite IT infrastructure changes to accommodate data streams, and extends to

\section{References}

Angeles, R. (2005). "RFID Technologies: Supply-Chain Applications and Implementation Issues," Information Systems Management, 22(1), pp. 5165.

Asif, Z. and M. Mandviwalla (2005). "Integrating the Supply Chain with RFID: A Technical and Business Analysis," Communications of the Association for Information Systems, 15(24), pp. 393-427.

Ayre, L.B. (2005). "Position Paper: RFID and Libraries" in Garfinkel, S. and B. Rosenberg (eds.) Wireless Privacy: RFID, Bluetooth and 802.11, Boston, MA: Addison Wesley/Prentice Hall, pp. 228-241.

Brackett, M.H. (1999) "Business Intelligence Value Chain," DM Review, March.

Bottani, E. (2008). "Reengineering, Simulation and Data Analysis of an RFID System," Journal of Theoretical and Applied Electronic Commerce Research, 3(1), pp. 13-29. the production of real-time business intelligence for decision makers that results from the implementation of desired decisionmaking improvements based on RFID implementations.

The IT Decision Chain, as fueled by the infusion of RFID technology involves an increasingly complex and comprehensive data gathering and analysis system capable of providing superior granularity of view on business processes for decision makers in retail channels. But, what starts with simple RFID chips concludes with a system that must be equal to the enormous volume and complexity of data that these chips have the potential to provide. Failure to analyze and plan for the infrastructure to accommodate the resulting data flow increases will potentially doom RFID implementations to disappointing outcomes.

Bottani, E., M. Bertolini, R. Montanari, and A. Volpi (2009a). "RFID-Enabled Business Intelligence Modules for Supply Chain Optimisation," International Journal of RF Technologies: Research and Applications, 1(4), pp. 253-278.

Bottani, E., G. Ferretti, R. Montanari, and A. Rizzi (2009b). "The Impact of RFID Technology on Logistics Processes of the Fashion Industry Supply Chain," International Journal of RF Technologies: Research and Applications, 1(4), pp. 225-252.

Bottani, E. and A. Rizzi (2008). "Economical Assessment of the Impact of RFID Technology and EPC System on the Fast-Moving Consumer Goods Supply Chain," International Journal of Production Economics, 112(2), pp. 548-569.

Cazier, J.A., A. S. Jensen, and D.S. Dave (2008). "The Impact of Consumer Perceptions of Information Privacy and Security Risks on the Adoption 
of Residual RFID Technologies," Communications of the Association for Information Systems, 22(15), pp. 235-256.

Chang, S.-I., S.-Y. Hung, D.C. Yen, and Y.J. Chen (2008). "The Determinants of RFID Adoption in the Logistics Industry - A Supply Chain Management Perspective," Communications of the Association for Information Systems, 23(12), pp. 197-218.

Chawathe, S.S., V. Krishnamurthy, S. Ramachandran, and S. Sarma (2004). "Managing RFID Data," Proceedings of the 30th Very Large Databases Conference (VLDB'04), Toronto, Canada, August 31 September 3, pp. 1189-1195.

CILT World (2004). "RFID - Could it Spell the End of the Super-Store Checkout?" CILT World, 10, July, p. 23.

Clauberg, R. (2004). "RFID and Sensor Networks: From Sensor/Actuator to Business Application," RFID Workshop, University of St. Gallen, Switzerland, September 27, pp. 1-6.

Curtin, J., R.J. Kauffman, and F.J. Riggins (2007). "Making the 'MOST' out of RFID Technology: A Research Agenda for the Study of the Adoption, Usage and Impact of RFID," Information Technology Management, 8(2), pp. 87-110.

Delen, D., B.C. Hardgrave, and R. Sharda (2007). "RFID for Better SupplyChain Management through Enhanced Information Visibility," Production and Operations Management, 16(5), pp. 613-624.

Dos Santos, B.L and L.S. Smith (2008). "RFID in the Supply Chain: Panacea or Pandora's Box?" Communications of the ACM, 51(10), pp. 127-131.

Dubey, P. (2005). "Recognition, Mining and Synthesis Moves Computers to the
Era of Tera," Technology@Intel Manazine, February, pp. 1-10.

Dutta, A., H.L. Lee, and S. Whang (2007). "RFID and Operations Management: Technology, Value, and Incentives," Production and Operations Management, 16(5), pp. 646-655.

Faupel, T., J. Strueker, and D. Gille (2008). "Performance Improvements Based on RFID - Empirical Findings from a Cross-Sectoral Study," Proceedings of the 14th Americas Conference on Information Systems (AMCIS'08), Toronto, Canada, August 14-17, pp. 1-11.

Fichman, R.G. (2001). "The Role of Aggregation in the Measurement of IT-Related Organizational Innovation," MIS Quarterly, 25(4), pp. 427-455.

Friedman, T. and K.H. Strange (2004). "Architecture: The Foundation of Business Intelligence," Gartner Research, AV-22-6453, April 14, pp. 1-4.

Fulk, J. and B. Boyd (1991). "Emerging Theories of Communication in Organizations," Journal of Management, 17(2), pp. 407-446.

Golab, L. and M.T. Ozsu (2003). "Issues in Data Stream Management," ACM SIGMOD Record, 32(2), pp. 5-14.

Gonzalez, H., J. Han, X. Li, and D. Klabjan (2006). "Warehousing and Analyzing Massive RFID Data Sets," Proceedings of 22nd International Conference on Data Engineering (ICDE'06), Atlanta, Georgia, April 3-7, pp. 83-92.

Hannula, M. and V. Pirttimaki (2003). "Business Intelligence Empirical Study on the Top 50 Finnish Companies," Journal of American Academy of Business, Cambridge, 2(2), pp. 593-599. 
Hardgrave, B.C., D.J. Armstrong, and C.K. Riemenschneider (2007). "RFID Assimilation Hierarchy," Proceedings of the 40th Annual Hawaii International Conference on System Sciences (HICSS'07), Big Island, Hawaii, January 3-6, pp. 224b.

Hardgrave, B.C., J. Aloysius, and S. Goyal (2009). "Does RFID Improve Inventory Accuracy? A Preliminary Analysis," International Journal of RF Technologies: Research and Applications, 1(1), pp. 44-56.

Hornyak, T. (2008). "RFID Powder," Scientific American, February, pp. 68-71.

Huber, G.P. (1990). "A Theory of the Effects of Advanced Information Technologies on Organizational Design, Intelligence, and DecisionMaking," Academy of Management Review, 15(1), pp. 47-71.

Janz, B.D., M.G. Pitts, and R.F. Otondo (2005). "Information Systems and Health Care II: Back to the Future with RFID: Lessons Learned - Some Old, Some New," Communications of the Association of Information Systems, 15, pp. 132-148.

Jeyaraj, A., A. Sengupta, and V. Sethi (2008). "Stages in Adoption of RFID Innovations by Organizations: Identifying Facilitators and Inhibitors," Proceedings of the 14th Americas Conference on Information Systems (AMCIS'08), Toronto, Canada, August 14-17, pp. 1-7.

Kamoun, F. (2008). "Rethinking the Business Model with RFID," Communications of the Association of Information Systems, 22, pp. 635658.

Keshiwani, H. (2005). "Understanding RFID System Components," BusinessWorks, Inc., http://businessworks.blogspot.com/2 005/01/understanding-rfid-system- components.html (current September 23, 2009).

Lee, H. (2004). "The Triple-A Supply Chain," Harvard Business Review, 82(10), pp. 102-112.

Levinson, M. (2003). "The RFID Imperative," ClO Magazine, December 1.

Lewis, S. (2004). "A Basic Introduction to RFID Technology and Its Use in the Supply Chain," White Paper, Laran RFID, January, pp. 1-30.

Loebbecke, C. (2007). "Piloting RFID along the Supply Chain: A Case Analysis," Electronic Markets, 17(1), pp. 29-37.

Melski, A., J. Mueller, A. Zeier, and M. Schumann (2008). "Assessing the Effects of Enhanced Supply Chain Visibility through RFID," Proceedings of the 14th Americas Conference on Information Systems (AMCIS'08), Toronto, Canada, August 14-17, pp. 1-12.

Ni, L.M., Y. Liu, Y.C. Lau, and A.P. Patil (2004). "LANDMARC: Indoor Location Sensing Using RFID," Wireless Networks, 10(6), pp. 701710.

Niederman, F., R.G. Mathieu, R. Morley, and I.-W. Kwon (2007). "Examining RFID Applications in Supply Chain Management," Communications of the ACM, 50(7), pp. 93-101.

Porter, M.E. (1990). The Competitive Advantage of Nations, New York, NY: Free Press.

Sellitto,C., S. Burgess, and P. Hawking (2007). "Information Quality Attributes Associated with RFIDDerived Benefits in the Retail Supply Chain," International Journal of Retail \& Distribution Management, 35(1), pp. 69-87.

Sengupta, A. and V. Sethi (2007). "AMCIS 2007 Panel Summary: The Promise of RFID Technologies," Communications of the Association 
for Information Systems, 20, pp. 944957.

Smith, H. and B. Konsynski (2003). "Developments in Practice X: Radio Frequency Identification (RFID) - An Internet for Physical Objects," Communication of the Association for Information Systems, 12, pp. 301311.

Soon, C.B. and J.A. Gutiérrez (2008). "Effects of the RFID Mandate on Supply Chain Management," Journal of Theoretical and Applied Electronic Commerce Research, 3(1), pp. 81-91.

Van der Vorst, J.G.A.J., A.J.M. Beulens, W. De Wit, and P. Van Beek (1998). "Supply Chain Management in Food Chains: Improving Performance by Reducing Uncertainty," International Transactions in Operational Research, 5(6), pp. 487-499.

Vedder, R.G., M.T. Vanecek, C.S. Guynes, and J.J. Cappel (1999). "CEO and ClO Perspectives on Competitive Intelligence," Communications of the ACM, 42(8), pp. 108-116.

Viehland, D. and A. Wong (2007). "The Future of Radio Frequency Identification," Journal of Theoretical and Applied Electronic Commerce Research, 2(2), pp. 74-81.

Wamba, S.F. and H. Boeck (2008). "Enhancing Information Flow in a Retail Supply Chain Using RFID and
EPC Network: A Proof-of-Concept Approach," Journal of Theoretical and Applied Electronic Commerce Research, 3(1), pp. 92-105.

Want, R. (2004). "The Magic of RFID," ACM Queue, 2(7), pp. 40-48.

Watson, H.J., B.H. Wixom, J.A. Hoffer, R. Anderson-Lehman, and A.M. Reynolds (2006). "Real-time Business Intelligence: Best Practices at Continental Airlines," Information Systems Management, 23(1), pp. 718.

Weier, M.H. (2009). "RFID-Based Dispensers Redefining BI for Coke," InformationWeek, June 8, pp. 30, 32.

Weinstein, R. (2005). "RFID: A Technical Overview and Its Application to the Enterprise," IT Professional, 7(3), pp. 27-33.

Xiao, Y., S. Yu, K. Wu, Q. Ni, C. Janecek, and J. Nordstad (2007). "Radio Frequency Identification: Technologies, Applications, and Research Issues," Wireless Communications \& Mobile Computing, 7(4), pp. 457-472.

Zang, C., Y. Fan, and R. Liu (2008). "Architecture, Implementation and Application of Complex Event Processing in Enterprise Information Systems Based on RFID," Information Systems Frontiers, 10(5), pp. 543-553. 


\section{About the Authors}

Xihui Zhang is an Assistant Professor of Computer Information Systems in the College of Business at the University of North Alabama. He earned a Ph.D. in Business Administration with a concentration on Management Information Systems from the University of Memphis. His teaching and research interests include technical, behavioral, and managerial aspects of Information Systems. He has published numerous articles in refereed journals and conference proceedings. He serves on the Editorial Review Board for several academic IS journals such as Journal of Computer Information Systems and Journal of Information Technology Education.

David W. Nickels is an Associate Professor of Computer Information Systems in the College of Business at the University of North Alabama. He earned a Ph.D. in Business Administration (concentration in MIS) from the University of Memphis. His primary areas of research are IT-business alignment, teaching and learning in information systems programs, organizational justice, and e-commerce. He has published in journals such as the Communications of the AIS, International Journal of Entrepreneurship, Franklin Business \& Law Journal, and Academy of Entrepreneurship Journal. Professor Nickels received a Distinguished Research Award at the Allied Academies Spring 2010 International Conference.

Thomas F. Stafford is an Associate Professor of Management Information Systems in the Fogelman College of Business and Economics at the University of Memphis. Professor Stafford is Editor in Chief of ACM's Data Base for Advances in Information Systems, and he holds the Ph.D. in MIS from University of Texas - Arlington, as well as the Ph.D. in Marketing from University of Georgia. 